\title{
Study on Teaching Strategy of Versification in Ancient Chinese Course of Local Application-oriented University
}

\author{
Yu Zhandong \\ (School of Literature, Xi'an University, Xi'an, Shaanxi, 710065)
}

Keywords: Versification; Teaching contents; Teaching method

\begin{abstract}
Versification is one of the important contents of ancient Chinese course of colleges and universities, but the difficulty in teaching and learning is the common phenomenon. By rationally planning the teaching contents of versification and consciously using the scientific principle of phonology to guide the teaching, the knowledge of ancient Chinese literature is used for versification analysis in combination with a number of poetries, to enable students to acquire perceptual knowledge when learning the theory of versification, thus improving the teaching quality and effects of versification in ancient Chinese course of colleges and universities.

As one of the public elementary courses for all students of Department of Chinese Language and Literature, ancient Chinese course refers to an important instrumental course. Students are required to master such basic knowledge as characters, vocabulary, grammar and phonology of ancient Chinese, and be capable of understanding writings in classical Chinese of general difficulty, drawing inferences, comprehending by analogy and analyzing relevant linguistic phenomenon in materials written in classical Chinese with the knowledge learned. In the meantime, ancient Chinese course can train students' ability in aesthetic appreciation, historical comparison, theoretical thinking and writing, familiarize students with the wise words and exemplary conduct of people with lofty ideals in China, and make students learn the profound humanist spirit in the excellent national culture, to cultivate perfect personality and improve the comprehensive quality. As a local application-oriented university, however, another teaching objective of ancient Chinese course is to lay a solid foundation for our graduates majoring in ancient Chinese to be competent in Chinese teaching of middle and primary schools, esp. teaching of ancient literature works.

China has always been regarded as a nation of poetry and the creation of modern-style poetry even reaches an unprecedented height. We are responsible for inheriting such precious cultural wealth. From another point of view, most of the students graduated from Department of Chinese Language and Literature of local application-oriented university are engaged in Chinese teaching in middle and primary school. And seen from the contents of Chinese teaching in primary school, under the trend of curriculum reform, classical poetry will be a key teaching point for teachers of middle and primary school along with the use of Chinese textbook uniformly edited by Ministry of Education of PRC. Then, as a cradle of cultivating Chinese teachers for future, how should teachers of Department of Chinese Language and Literature of local application-oriented university enable these Chinese teachers to well master the versification of modern-style poetry is a difficult point of our versification teaching. However, seen from the actual situation of teaching now, versification only takes up a small portion in ancient Chinese course, and is even deliberately avoided by some universities. The reason is that, ancient Chinese course takes the classical style of writing of Pre-Qin and Han Dynasties as the main teaching objective, so most teachers lay the emphasis on teaching classical style of writing and linguistic phenomenon of Pre-Qin and Han Dynasties, and neglect the versification part which is arranged later. Moreover, certain phonology knowledge is the basis of learning versification well and phonology itself is a difficult point for students, but most students just have a smattering of it. Under such a status, it is really difficult for students to learn versification well. Therefore, higher requirements are raise for versification teaching.

In our opinion, versification teaching of local application-oriented university shall give prominence to the key points and have a definite object. From an overall view, the teaching contents of versification shall include evolution of poem style, rhythm characteristics of modern-style poetry, syntax of modern-style poetry and identification of entering tone characters, but emphasis shall be
\end{abstract}


given to rhythm-using and level \& oblique tone of modern-style poetry in rhythm characteristics of modern-style poetry rather than equal stress to the four parts.

The first part - evolution of poem style, is relatively simple for students as they have accumulation of previous ancient literature course. Our task is to guide students to review the development stages of classical poetry in China starting with poetry of the pre-Qin period represented by The Book of Songs and The Songs of Chu, ancient poetry of Han-Wei and Six Dynasties represented by Yuefu Poem of the Han Dynasty, five-character poetry and seven-character poetry of scholars, "Yongming Style" poetry of the Qi and Liang Dynasties represented by Shen Yue and Xie Tiao, as well as regulated verse of the Tang Dynasty. Classified from the perspective of poem style, classical poetry is now simply classified into ancient poetry and modern-style poetry. Also called "antiquity", the former mainly includes classical poetry of Yuefu in the Han and Wei Dynasties, folk songs of Yuefu in the Northern and Southern Dynasties, and scholar poems of these times as well as imitation works by later ages. Modern-style poetry is also called "modern poems" and refers to the metrical poetry formed in the early Tang Dynasty and characterized by level \& oblique tone and antithesis. Modern-style poetry is formed based on "Yongming Style" poem. Through further efforts of some poets in the early Tang Dynasty, its rhythm is further perfected and the form of Chinese modern-style poetry is finally fixed and standardized. Modern-style poetry refers to the orthodox of China's poem style. Therefore, it is necessary to make students understand that modern-style poetry and ancient poetry are distinguished in terms of form rather than time.

The second part - rhythm characteristic of modern-style poetry, is the key and difficult point of our teaching. To be specific, it includes sentence pattern, rhythm-using, level \& oblique tone and antithesis of modern-style poetry. The so-called "rhythm" is explained in Origin of Chinese Characters as follows: "rhythm, uniform distribution." It is also noted in Origin of Chinese Characters that "rhythm is just the unified rules and forms to be followed, thus called uniform distribution." As a result, "rhythm" refers to the rules and forms in terms of number of words and sentences, antithesis, level \& oblique tone, rhyming, form and temperament to be observed during creation of Chinese ancient verses, ditties, odes and songs.

Compared with ancient poetry, the first feature of modern-style poetry is fixed sentence. This visualized feature is easy to understand. Modern-style poetry is classified into five-character and seven-character. Regulated verse includes poem of eight lines and that of four lines and those more than eight lines are called long regulated verse. As for regulated verse of eight lines, every two lines form a couplet, i.e. Shoulian, Hanlian, Jinlian and Weilian. For each couplet, the first line is called "the first pair part" while the second line is called "the second pair part". This part does not require too much teaching time. It is only necessary for students to understand related concepts.

The second feature refers to strict rhyme. Rhythm-using in modern-style poetry is a key and difficult point of teaching. As we have discussed above, many contents of this feature involve the knowledge of phonology, which is difficult to master for students. They either discard it after learning or just have a smattering of it. So this part will take us great effort in both recalling students of the knowledge in phonology and make them master the rules of rhyming in modern-style poetry. First, we should help student ravel out two different concepts, namely, "rhyme" and "vowel". "Vowel" refers to the part after the initial of a syllable, including head vowel, essential vowel and tail vowel (regardless of the tone). But "rhyme" only requires the same essential vowel and tail vowel instead of caring about whether there is head vowel or the head vowel is identical. In addition, rhyme also requires the same tone. The case of same essential vowel and tail vowel with different tone does not refer to the same rhyme. Secondly, students should know "Pingshui Rhyme" the basis of rhyming in modern-style poetry. Since the rhyme class of poetry of the Tang Dynasty is significantly different from that of previous dynasties, not only different from that of ancient times, but also that of Wei and Jin Dynasties However, after the Song Dynasty, scholars just follow the rhyme of the Tang Dynasty when composing poems, so it is necessary to introduce the poetic rhyme of the Tang Dynasty to students. Lu Fayan of the Sui Dynasty wrote Qie Yun and Chen Pengnian, et al. of the Northern Song Dynasty modified it into Guang Yun which is 
popular all over the world. Totally 206 rhymes are introduced in Guang Yun, too detailed and not completely in conformity with the phonetics of that time. However, as stipulated by scholar of the Tang Dynasty, the similar rhymes can "be used simultaneously", and Liu Yuan - from Pingshui (now Linfen of Shanxi) of the Southern Dynasty simply combined the rhymes that can be used simultaneously in Guang Yun into 107 rhymes, which was later reduced into 106 rhymes by later scholars. These 106 rhymes are named Pingshui Rhyme, generally called "poetic rhyme" "11. Poets in the Tang Dynasty do not use rhyme according to Pingshui Rhyme, but Pingshui Rhyme can be used to explain the rhyme-using of poets in the Tang Dynasty and serve as the basis of rhyming of modern-style poetry as they follow the rules of "simultaneous use" and "exclusive use". Therefore, students shall get familiar with the vowel of 106 rhymes in Pingshui Rhyme and know that they can look up Table of Common Characters of Poetic Rhyme when judging the rhyme-using of modern-style poetry. The rhyme-using features of modern-style poetry mainly includes: 1) modern-style poetry generally adopts level rhyme rather than oblique rhyme; but ancient poetry can either use level rhyme or oblique rhyme. 2) Modern-style poetry must adopt the same rhyme in one poem, even for long regulated verse as long as ten lines; while ancient poetry allows rhyme changing. 3) Modern-style poetry does not allow "off rhyme", that is, the rhyme must refer to the character with the same vowel rather than similar vowel; while for ancient poetry, characters of similar vowel can be used. 4) For modern-style poetry, rhyming is usually contained in even lines apart from the first line. It is different for ancient poetry, that is, rhyming can be either contained in odd or even lines or both. This part must be fully demonstrated to students in combination with specific poetries. After all, speaking with facts is better than theoretical teaching.

The third feature is following level \& oblique tone. Another key and difficult point of versification teaching is level \& oblique tone of modern-style poetry. Level \& oblique tone is the most key factor of composing modern-style poetry. The knowledge of phonology is also involved here. Level \& oblique tone is the classification of four tones by ancient Chinese people. "Level tone" refers to the even tone of four tones in ancient Chinese, while "oblique tone" refers to falling-rising tone, falling tone and entering tone. The rule for correspondence between the four tones in ancient Chinese and those in standard Chinese: "even tone is divided into level tone and rising tone, voiced sound is classified into falling tone, and entering tone, into level tone, rising tone, falling-rising tone and falling tone". It is necessary to show the correspondence table of level \& oblique tones, four tones in ancient Chinese and four tones in standard Chinese to students. From the perspective of standard Chinese, both level tone and rising tone are level, while falling-rising tone and falling tone are oblique. It is all right to convert ancient characters in entering tone into falling-rising tone and falling tone in standard Chinese because falling-rising tone, falling tone and entering tone all belong to oblique tone. Only characters converted from entering tone into level tone and rising tone should be remembered, and such characters are limited. So it is recommended to present a table of such common characters to students. However, the basic requirement on level \& oblique tone for regulated verse is that level tone and oblique tone in the same line shall be identical and alternating, so as to pursue cadence effect. For example, "level-level-oblique-oblique-level" or "oblique-oblique-level-level-oblique". But it should be noted that three level (oblique) tones are not allowed at the end of a line, e.g.: "oblique-oblique-level-level-level" or "level-level-oblique-oblique-oblique". However, three level (oblique) tones are allowed at the beginning, e.g.: "level-level-level-oblique-oblique" or "oblique-oblique-oblique-level-level". It can thus be analyzed that the four basic sentence patterns of five-character regulated verse can be considered as adding a syllable to the form of "oblique-oblique-level-level" or "level-level-oblique-oblique". Therefore, we can conclude that the four basic sentence patterns of regulated verse are: (A) oblique-oblique-level-level-oblique, (B) level-level-oblique-oblique-level, (C) level-level-level-oblique-oblique and (D) oblique-oblique-oblique-level-level. Four basic sentence patterns of seven-character regulated verse are just to add the inverse "level-level" or "oblique-oblique" at the front of those of five-character regulated verse. Alternative use of these four sentence patterns just form five (seven)-character regulated verse of diversified styles. The second requirement of regulated verse in terms of level \& oblique tone is the rule of "adhering" and 
"opposing". That is to say, in the same couplet, level tone should oppose to oblique tone, and for two couplets, level tone shall adhere to oblique tone. "Adhering" refer to that the level \& oblique tone of the second character in the second pair part of previous couplet should be the same as that in the first pair part of the next couplet. That is, level (oblique) tone adheres to level (oblique) tone. "Opposing" refers to that the level \& oblique tone of the second character in the first pair part and the second pair part of the same couplet shall be opposite. That is, level (oblique) tone opposites to oblique (level) tone. Adhering and opposing plays the role of diversifying tones. The level \& oblique tone of the two lines in the same couplet will be similar if they do not oppose, and that of two couplets will be similar if they do not adhere. The knowledge of "adhering and opposing" can help students understand the level \& oblique tone of long regulated verse. No matter how long the regulated verse is, the level \& oblique tone is just arranged by following the rule of adhering and opposing. There is a few examples of non-adhering in poetry of the Tang Dynasty, but seldom non-opposing case. Some textbooks may suggest presenting a number of fixed patterns of level \& oblique tone to students, e.g.: starting with oblique tone or level tone, so that students can remember them. But we think it is unnecessary. Such too detailed presentation will increase the memory work of students. Therefore, we recommend presenting abundant poems to students to mark the level \& oblique tones, so that they can comprehensively combine them with the rhyme and adhering \& opposing laws of the learnt poetry. Under normal condition, after learning of six or seven poems, $95 \%$ of the students can correctly judge the level \& oblique tone of the first line, and then correctly mark the level \& oblique tone of a whole poem by following the laws. But it should be noted that poems for practice must have level \& oblique tones conforming to the laws. After the students get a mastery of the basic rhyme and level \& oblique tone laws of regulated verse, the teacher shall further explain the problem of "remedying metrically irregular line" (remedying the line with only one level tone, special remedying and remedying by the second pair part) in modern-style poetry in combination with detailed poems. The issue of "remedying metrically irregular line" is also difficult to understand for students. So it is necessary to slow down, clearly state the laws and demonstrate with specific poems.

It should be noted that in the process of learning the rhyme of modern-style poetry, the identification of entering tone is sometimes hard for them due to variations of phonetics in ancient and modern Chinese. During class exercises, students usually reflect that why does a certain character belong to entering tone since it is plainly first tone or second tone in standard Chinese? That is also a mistake students are prone to. As a result, the first requirement is that students should learn to use such reference books as Word-Ocean Dictionary, Pingshui Rhyme, The Standard Phrase Dictionary and New Pingshui Rhyme. Moreover, we summarized the evolution rules of the sounds falling to entering tone in Chinese ancient phonetic system in standard Chinese to teach them to students, and summarized the Table of Identifying Entering Tone Characters so that students can accurately judge the entering tones when learning the rhyme of modern-style poetry.

The fourth feature is antithesis. It is hardly a difficult point for students and teacher should mainly clearly explain the concept, type and position of antithesis in combination with specific poems. In addition, we usually require students to read or recite ABC Sound Meters in Chinese Poetry by heart.

As for the syntactic features of modern-style poetry, we only briefly introduce it to students, and proceed with flexible use (it is common to see flexible use of parts of speech in modern-style poetry), dislocation (position of the subject, object, attribute and adverbial modifier different from general pattern is allowed), omission (relevant words or constituents are omitted) and compression (it can be seen as compression by two clauses) in combination with specific verses.

After teaching of all contents, we should organize students for plenty of practices. So far, most students can basically infer the level \& oblique tone pattern of the first line according to the level \& oblique tone of the second and the last characters of the first line in the first step. Then, infer the level \& oblique tone pattern of the whole verse according to the level $\&$ oblique tone of the first line by following the laws of adhering and opposing. And last, check whether the actual character pronunciation is inconsistent with the pattern. In case of any inconsistency, mark with $\mathrm{O}$ at the 
positions where both level tone and oblique tone are applicable. Upon remedying metrically irregular line, mark $\boldsymbol{\Delta}$ under "irregular character" and add • for "remedying".

In conclusion, as long as teachers engaged in teaching meters in Chinese poetry can rationally plan the contents of versification and consciously use the knowledge of phonetics and ancient literature to guide teaching, the quality of versification teaching in ancient Chinese course of universities will be doubtlessly improved with deserved effects.

\section{Acknowledgement}

Fund program: Educational Reform Project for Ancient Chinese Course of Xi'an University (KGB201809,KGC201810)

\section{Reference}

[1]Yao zhenwu, The origin of human language and the linguistic significance of ancient Chinese,Chinese Research[J],2010:2

[2]Bo shousheng, The puzzling and thinking of ancient Chinese Teaching,Chinese University Teaching[J],2007.7(6):15-18

[3]Zhang jusan, The current situation and strategy adjustment of ancient Chinese teaching in University,Research on Continuing Education[J],2017.10(23):25-31

[4]Wang wenjing, The application of "ancient writing" knowledge in ancient Chinese Teaching,Modern Chinese[J],2017.12(14)35-37

[5]Zhu rui,How to stimulate students' interest in learning ancient Chinese,Chinese character culture[J],2017.11(12)24-26

[6]Wang Li. Ancient Chinese (Volume IV) [M]. Beijing: ZhongHua Book Company, 2010:1518. 